\title{
Thermodynamic Investigation of New High-Strength Low-Alloy Steels with Heusler Phase Strengthening for Welding and Additive Manufacturing: High-Throughput CALPHAD Calculations and Key Experiments for Database Verification
}

\author{
Xin Wang ${ }^{1} \cdot$ Soumya Sridar $^{1} \cdot$ Wei Xiong ${ }^{1}$ (1)
}

Submitted: 17 April 2020/in revised form: 30 June 2020/Published online: 30 July 2020

(C) ASM International 2020

\begin{abstract}
High-strength low-alloy (HSLA) steels often comprise of $\mathrm{Cu}$ clusters and $\mathrm{M}_{2} \mathrm{C}$ (M: Mo, Cr) carbides as strengthening particles. In this work, three new HSLA steels with alternative strengthening phases, $\mathrm{Fe}_{2} \mathrm{SiTi}$ and $\mathrm{Ni}_{3} \mathrm{Ti}$, are investigated by using HSLA-115 steel as the reference. To evaluate the weldability for potential fabrication using casting, welding, and additive manufacturing, freezing ranges are studied using differential thermal analysis (DTA), and CALPHAD (Calculation of Phase Diagrams) approach under equilibrium and nonequilibrium conditions. While the cooling signals in the DTA analysis are not pronounced enough for thermal analysis, the trend of freezing range change based on the nonequilibrium and equilibrium calculations are consistent with the heating signals. High-throughput calculations are performed to deduce the effect of variation of each alloying element on the freezing range. Moreover, the experimental and calculated phase fractions and compositions of the as-cast and heat-treated alloys were compared. Though CALPHAD
\end{abstract}

This article is an invited paper selected from presentations at "PSDK XIV: Phase Stability and Diffusion Kinetics-Gibbs: Phase

Equilibria, Diffusion and Materials Design" held during MS\&T'19, September 29-October 3, 2019, in Portland, Oregon. The special sessions were dedicated to honor Dr. Patrice Turchi, recipient of the ASM International 2019 J. Willard Gibbs Phase Equilibria Award "for outstanding and pioneering contributions in the application of first-principles, quantum-mechanical calculations to the modeling of phase equilibria and thermodynamic behavior of alloys." It has been expanded from its original presentation.

Wei Xiong

w-xiong@outlook.com; weixiong@pitt.edu;

http://www.pitt.edu/ weixiong

1 Physical Metallurgy and Materials Design Laboratory, Department of Mechanical Engineering and Materials Science, University of Pittsburgh, Pittsburgh, PA 15261 model-prediction can provide valuable insights into the phase stability of these new alloys, there is a remarkable difference regarding phase fraction and composition of individual phases. Therefore, this study indicates that the application of the CALPHAD approach in new alloy discovery requires a careful model-validation and database calibration.

Keywords CALPHAD · Heusler phase - HSLA steels · thermal analysis - thermodynamics

\section{Introduction}

Copper-bearing high strength low alloy (HSLA) steels with low carbon content such as HSLA-80, HSLA-100, and HSLA-115 (numbers denote the minimum tensile yield strength in ksi) steels were developed for naval applications, owing to their high strength, excellent low-temperature toughness and good weldability. ${ }^{[1]}$ This class of steels are cheap and involves low fabrication costs, and hence, it is used in applications such as the construction of ship hulls and offshore platforms. ${ }^{[2-4]}$ The loss of strength due to the low carbon content is compensated by the addition of $\mathrm{Cu}$. The high strength in Cu-bearing HSLA steels is attained due to the co-precipitation of BCC-Cu clusters, concomitantly with $\mathrm{M}_{2} \mathrm{C}$ (M: Mo as major species, $\mathrm{Cr}$ and $\mathrm{Fe}$ are minor) precipitates during aging. ${ }^{[5]}$ The superior weldability is due to the very low carbon content ( $\leq 0.06$ wt.\%). This ensures that the composition of these steels is located in Zone I of the Graville weldability diagram, ${ }^{[6]}$ which indicates good resistance to hydrogen-induced cracking. Excellent low-temperature impact toughness can be attributed to the dissolution of the 
cementite, which provides carbon necessary for the precipitation of $\mathrm{M}_{2} \mathrm{C} .{ }^{[5]}$ In addition, $\mathrm{Nb}$ is added in small amounts to inhibit the grain growth during austenitization by inducing the precipitation of carbides. ${ }^{[7]}$ The superior properties achieved due to the synergistic effects from the above-mentioned precipitates and the alloy composition has facilitated $\mathrm{Cu}$-bearing HSLA steels to be a candidate material for naval applications.

In recent years, there has been an increasing interest in steels that can be hardened by the precipitation of intermetallic phases. Fe-Si-Ti based alloys received special attention as it was found to be capable of forming a large volume fraction of intermetallic precipitates. ${ }^{[8,9]}$ It has been reported that the addition of $\mathrm{Si}$ and $\mathrm{Ti}$ to low carbon steels lead to the precipitation of ordered metastable intermetallic phase, $\mathrm{Fe}_{2} \mathrm{SiTi}$ in much higher fractions $(\sim 6 \%)$ than the usual amount of strengthening precipitates that form in micro-alloyed steels such as HSLA-115 steels. ${ }^{[10]}$ The age hardening behavior of Fe-Si-Ti alloys was investigated initially by Wasmuth ${ }^{[11]}$ and further by other researchers, ${ }^{[12,13]}$ and it was found that there is a fine dispersion of spherical coherent precipitates that were responsible for the hardening of these alloys. Jack ${ }^{[14]}$ reported that these precipitates are $\mathrm{Fe}_{2} \mathrm{SiTi}$, and the crystal structure was determined to be an ordered $\mathrm{L} 22_{1}$ face-centered cubic (FCC) crystal structure, which is the same as the Heusler phase. The resulting precipitation hardening leads to extremely high mechanical properties such as yield strength, strain hardening, and strain to fracture. ${ }^{[10]}$ In addition to this, these alloys can be solution treated with ferrite as the matrix phase such that no allotropic transformation occurs when quenched from the solution treatment temperature, which also contributes to the strengthening of this material. ${ }^{[15]}$ Low carbon steels with significant $\mathrm{Si}$ and $\mathrm{Ti}$ additions are expected to be promising candidate materials for automotive as well as naval applications due to their hardening behavior and the presence of solute elements with low density, leading to high strength in conjunction with substantial weight reduction.

It is known that the currently available commercial multicomponent thermodynamic databases for steels developed using the CALPHAD (Calculation of Phase Diagrams) method are efficient in predicting the phase equilibria in conventional steels. ${ }^{[16-20]}$ However, the applicability of these databases for newly designed steels with unconventional precipitates has not been explored until now. Hence, steels with a composition close to the conventional $\mathrm{Cu}$-bearing HSLA-115 steels with strengthening precipitates other than $\mathrm{M}_{2} \mathrm{C}$, were designed using a high-throughput CALPHAD-based ICME (Integrated Computational Materials Engineering) framework. ${ }^{[21,22]}$ The desired compositions were obtained by optimizing material properties such as the amount of beneficial and detrimental phases as well as the freezing range. These attributes were determined using the CALPHAD method, and high-throughput screening was performed using an inhouse ICME code. ${ }^{[22]}$ In order to achieve the highest volume of the $\mathrm{Fe}_{2} \mathrm{SiTi}$ phase, $500{ }^{\circ} \mathrm{C}$ is chosen as the temperature to optimize the composition. Further, to understand the effect of $\mathrm{Si}$, another composition (siliconand niobium-free steel) was designed with a silicon-free strengthening phase such as $\mathrm{Ni}_{3} \mathrm{Ti}$, as this phase is known to act as a strengthening precipitate in several other steels. ${ }^{[23-25]}$ Further details about this optimization method will be described elsewhere. ${ }^{[26]}$

In this study, the transition temperatures and phase transformations for the steels designed with alternative strengthening precipitates and the HSLA-115 steel are investigated. The liquidus and solidus temperatures and the freezing range as well as the microstructure of as-cast and heat-treated alloys are determined using thermal analysis and microstructure characterization, respectively. These experimentally determined quantities are compared with their corresponding values predicted using the CALPHAD method (equilibrium and non-equilibrium calculations) to evaluate the applicability of the existing commercial thermodynamic database for the design of new steels with alternative strengthening precipitates.

\section{Materials and Methods}

\subsection{Experimental Methods}

Three different steels were designed using the aforementioned approach, and the composition of the designed alloys and the HSLA-115 steel are listed in Table 1. The Laves_C14 phase was found to be the only detrimental phase in all the designed steels. The crystallographic details about the beneficial and detrimental phases in the designed steels are summarized in Table 2. In order to cast the designed steels, pure metals (purity $>99.95$ wt.\%, Alfa Aeser, USA) were weighed in a high precision weighing balance (uncertainty $= \pm 0.1 \mathrm{mg}$ ) according to the elemental ratio for each steel as listed in Table 1. Button alloys weighing 10 grams were cast in an arc melter (ABJ338 manufactured, Materials Research Furnaces Inc., USA) with a copper crucible and under argon atmosphere. Pure Zirconium was used to remove the remnant oxygen present in the chamber. Each alloy was re-melted five times to ensure complete homogeneity with a total weight loss of less than $0.1 \%$. Similarly, a wrought plate of HSLA- 115 steel (manufactured by Concurrent Technologies Corporation, USA), whose composition is listed in Table 1, was melted in the arc-melter under the same conditions as the 
Table 1 Composition (in wt.\%) of the designed alloys and conventional HSLA-115 steels

\begin{tabular}{|c|c|c|c|c|c|c|c|c|c|c|c|c|}
\hline \multirow[t]{2}{*}{ Alloy } & \multirow[t]{2}{*}{ Strengthening phases } & \multicolumn{11}{|c|}{ Composition, wt.\% } \\
\hline & & $\mathrm{Ti}$ & $\mathrm{Al}$ & $\mathrm{Si}$ & $\mathrm{Nb}$ & $\mathrm{Ni}$ & $\mathrm{C}$ & $\mathrm{Cr}$ & $\mathrm{Cu}$ & $\mathrm{Mn}$ & Mo & $\mathrm{Fe}$ \\
\hline D1 & $\mathrm{Cu}$ and $\mathrm{Fe}_{2} \mathrm{SiTi}$ & 3 & 3.4 & 2.1 & 0.63 & 0.3 & 0.06 & 0.8 & 1.45 & 0.95 & 0.8 & Bal. \\
\hline D2 & $\mathrm{Cu}$ and $\mathrm{Fe}_{2} \mathrm{SiTi}$ & 2 & 2.6 & 1.6 & 0.63 & 0.3 & 0.06 & 0.8 & 1.45 & 0.95 & 0.8 & Bal. \\
\hline D3 & $\mathrm{Cu}$ and $\mathrm{Ni}_{3} \mathrm{Ti}$ & 2 & 0.3 & 0 & 0 & 8 & 0.06 & 0.4 & 1.45 & 0.95 & 0.8 & Bal. \\
\hline HSLA-115 & $\mathrm{Cu}$ and $\mathrm{M}_{2} \mathrm{C}$ & 0 & 0.03 & 0.23 & 0.03 & 3.43 & 0.053 & 0.66 & 1.27 & 0.98 & 0.57 & Bal. \\
\hline
\end{tabular}

Table 2 Crystallographic information for the secondary phases predicted to form in the designed steels

\begin{tabular}{lllccc}
\hline Phase & Structure & Space group & Pearson symbol & Strukturbericht notation & Effect \\
\hline $\mathrm{Fe}_{2} \mathrm{SiTi}$ & $\mathrm{FCC}$ & $\mathrm{Fm} \overline{3} \mathrm{~m}$ & $\mathrm{cF} 16$ & $\mathrm{~L} 2_{1}$ & Beneficial \\
$\mathrm{Laves}_{2} \mathrm{C} 14$ & Hexagonal & $\mathrm{P}_{3} / \mathrm{mmc}$ & $\mathrm{hP1}$ & $\mathrm{C} 14$ & Detrimental \\
$\mathrm{Ni}_{3} \mathrm{Ti}$ & Hexagonal & $\mathrm{P}_{3} / \mathrm{mmc}$ & $\mathrm{hP16}$ & $\mathrm{D} 0_{24}$ & Beneficial \\
$(\mathrm{Nb}, \mathrm{Ti}) \mathrm{C} / \mathrm{TiC}$ & $\mathrm{FCC}$ & $\mathrm{Fm} \overline{3} \mathrm{~m}$ & $\mathrm{cF} 8$ & $\mathrm{~B} 1$ & Beneficial \\
\hline
\end{tabular}

designed alloys in order to obtain the as-cast microstructure.

Small disc-shaped samples weighing nearly $200 \mathrm{mg}$ were prepared from the cast button alloys and heat treated at $600{ }^{\circ} \mathrm{C}$ for $24 \mathrm{~h}$ for the thermal analysis. Differential thermal analysis (DTA) was performed using Netzsch DSC 404 F1 (Netzsch, Germany). The samples were placed inside alumina crucible, and the instrument was evacuated and backfilled with Argon prior to the tests. During the experiment, the furnace and the sample chambers were purged with high purity Argon gas with a flow rate of $20 \mathrm{ml} / \mathrm{min}$. The temperature calibration was performed by measuring the melting points of high purity metals (99.999\% otherwise explicitly mentioned) such as $\mathrm{Bi}$, In, $\mathrm{Al}, \mathrm{Au}, \mathrm{Fe}(99.99 \%)$, Ni using an $\mathrm{S}$ type thermal couple $(\mathrm{Pt}-\mathrm{Pt} / \mathrm{Rh})$ with a temperature range of $20-1650{ }^{\circ} \mathrm{C}$. The heating and cooling rates were $10 \mathrm{~K} / \mathrm{min}$, and the samples were heated from room temperature to $800{ }^{\circ} \mathrm{C}$ and then heated to $1580{ }^{\circ} \mathrm{C}$ and eventually cooled. The heating and cooling cycles between 800 and $1580{ }^{\circ} \mathrm{C}$ were repeated three times, and the curves obtained from the second run were used for demonstrating how the liquidus and solidus temperatures were determined. The solidus temperature was taken as the onset of the first peak using the two tangents method, and the liquidus temperature was taken as the peak temperature of the last peak on the heating curves. $^{[27]}$

One part of the cast button alloy was cut and encapsulated inside quartz tubes under vacuum and back-filled with Argon for isothermal annealing at $600{ }^{\circ} \mathrm{C}$ for $480 \mathrm{~h}$ (20 days), which are considered to be long enough for equilibrium study. After annealing, the quartz tubes containing the annealed samples were subjected to quenching in ice-water to achieve rapid cooling to retain the phases that formed at $600{ }^{\circ} \mathrm{C}$ to room temperature. The other part of the cast button was utilized for characterizing the as-cast microstructure. The as-cast and annealed samples were hotmounted in a thermosetting resin for mechanical polishing. All the sample surfaces were ground from 400 to 1200 grit $\mathrm{SiC}$ emery papers. Further, cloth polishing was done using diamond and alumina suspensions comprising of 1 and $0.05 \mu \mathrm{m}$ particles to obtain a surface with a mirror finish. The as-polished surfaces were etched with $2 \%$ Nital $(2 \mathrm{ml}$ $\mathrm{HNO}_{3}+98 \mathrm{ml}$ ethanol) by immersing in the etchant for 10-30 s.

Extensive microstructure characterization was performed to understand the phase transformations in the ascast and annealed samples. The phase evolution was determined by viewing the etched as-cast and annealed samples under ZEISS Sigma 500 VP scanning electron microscope (SEM) in backscattered electron (BSE) mode operating at $20 \mathrm{kV}$. The elemental composition for each phase was determined using Oxford Aztec energy dispersive spectroscope (EDS) attached to the SEM. The reported values are an average of the compositions determined using EDS from 30 different points for each phase measured in 5 different regions. It is to be noted that the composition of carbon was not considered during the EDS measurements due to its limited sensitivity for light elements (atomic number $<11$ ), preventing it from measuring the carbon content accurately from the constituent phases. The fraction of each phase was estimated from the two-dimensional microstructure images obtained from SEM using the ImageJ software. The reported phase fractions are an average of the fractions determined from 10 different SEM images captured in backscattered electron mode (SEM/BSE). 


\subsection{Computational Methods}

The thermodynamic calculations for the designed and HSLA-115 steels were carried out using the Thermo-Calc software ${ }^{[28]}$ with the TCFE (v10) commercial database for steels. The equilibrium phase fraction as a function of temperature and the composition of phases at isothermal annealing temperature were calculated. Similarly, the nonequilibrium Scheil-Gulliver ${ }^{[29,30]}$ model was implemented to predict the solidification paths as well as the phase compositions of the as-cast designed and HSLA-115 steels. As carbon is an interstitial atom, its back-diffusion was taken into account in this calculation. These predicted values were utilized for comparison with the experimentally determined quantities to validate the applicability of the thermodynamic database for the designed and HSLA115 steels. In order to estimate the equilibrium freezing ranges for a large number of compositions, high-throughput calculations were performed using TC-API (ThermoCalc Application Programming Interface) toolkit, namely, TC-Python, which is based on the Python programming language.

\section{Results and Discussion}

\subsection{Thermal Analysis}

The freezing range, liquidus and solidus temperatures determined using DTA measurements as well as their counterparts calculated using the CALPHAD method (equilibrium and non-equilibrium) are presented in Fig. 1. Figure 1(a) and (b) shows the second heating and cooling curves along with the transition temperatures marked for each alloy, respectively. The two endothermic peaks in heating curves and exothermic peaks in cooling curves are found to be overlapping in D1-D3 alloys, and hence, it is hard to distinguish between the peaks for all the alloys. In the heating curves, the first visible onset of melting is solidus, and the peak corresponding to the last thermal event is the liquidus. ${ }^{[27]}$ It is easy to identify those two temperatures with heating curves, which is shown in Fig. 1(a). However, as shown in Fig. 1(b), the solidus temperature is the second onset temperature of the exothermic peak in the cooling curve, which is invisible for D1-D3 alloys. Thus, we will adopt the liquidus and solidus temperatures from heating curves, and the average values and standard deviations from the three measurements are listed in Table 3 and plotted in Fig. 1(c), (d) and (e). It is found that the deviation of liquidus, solidus, and the freezing range of the three times measurements are small. From Fig. 1(c), it is clear that the assumption considered in Scheil simulations ${ }^{[29,30]}$ and Lever rule, i.e., infinite diffusion in the liquid phase, always leads to the same liquidus temperature for the equilibrium and non-equilibrium calculations. However, the predicted temperature is found to be lower in comparison with the liquidus temperature determined from heating curves from DTA measurements, which is due to the time-dependent delay in heat transfer of the DTA instrument. ${ }^{[31,32]}$ There is a good agreement between the calculated and measured liquidus temperatures for D1 and D2 alloys, which consists of a lower amount of $\mathrm{Ni}$ and a higher amount of $\mathrm{Ti}, \mathrm{Al}$, and $\mathrm{Si}$. On the other hand, there is a significant difference between the predicted and measured liquidus temperatures for alloy D3 and HSLA-115 steel that contains less Al and Si and higher amount of $\mathrm{Nb}$.

It is clear from Fig. 1(d) that the predicted solidus temperatures using Scheil simulations are much lower than that obtained using the Lever rule and DTA measurements because negligible diffusion in the solid phase is assumed in the Scheil simulations. ${ }^{[29,30]}$ On the contrary, a complete diffusion is assumed in the solid phase during the equilibrium calculations. Moreover, the values predicted using Lever rule are in good agreement with that measured using DTA, as the solidus temperatures obtained using DTA are in the near-equilibrium state. It is known that for cooling DTA curves, the supercooling and rapid solidification will lead to the change of measured phase transformation temperature. Moreover, the characteristic response time for heat flow between the sample, crucible, thermal couple, furnace, wall will cause the deviation of solidus and liquidus in heating DTA curves, which has been verified by experiments. ${ }^{[31]}$ According to the discussion by Meco et al. ${ }^{[31]}$ and Boettinger et al., ${ }^{[32]}$ the temperature offset between the sample and thermocouple caused by the timedependent delay in heat transfer can be expressed by the following equations:

$T_{\text {measure }}^{\text {liq }}=T_{\text {sample }}^{\text {liq }}+\sqrt{\alpha}\left(\frac{2 t_{S, C}^{2} m_{S}\left(L+C_{p}^{S}\left(T_{u}-T_{L}\right)\right)}{m_{S} C_{p}^{c}\left(t_{S, C}+t_{W, C}\right)}\right)^{0.5}$

$T_{\text {measure }}^{\text {sol }}=T_{\text {sample }}^{\text {sol }}+\alpha \frac{t_{S, C}\left(t_{S, C} R^{\prime}+t_{W, C} R^{\prime}+t_{W, C}\right)}{t_{W, C}+t_{S, C}}$

where $T_{\text {measure }}^{\text {liq }}$ and $T_{\text {measure }}^{\text {sol }}$ are the measured liquidus and solidus temperature, respectively, $T_{\text {sample }}^{\text {liq }}$ and $T_{\text {sample }}^{\text {sol }}$ are the true liquidus and solidus temperature of the sample, $\alpha$ is the heating rate, $m$ is the weight, $C_{p}$ is the heat capacity, $t_{a, b}$ is the instrument time constant between component $\mathrm{a}$ and $\mathrm{b}, L$ is the latent heat of phase transformation, $T_{u}$ and $T_{L}$ are the upper and lower boundaries of the solid-liquid coexist region, and the notation $S$ is the sample, $C$ is the crucible, $W$ is the furnace wall. It is clearly that for a given system, 
Fig. 1 (a) Heat flow versus temperature heating curves obtained from DTA of the second run (b) Heat flow versus temperature cooling curves obtained from DTA of the second run, the comparison of the (c) Liquidus temperatures, (d) Solidus temperatures and (e) Freezing ranges for the designed and HSLA-115 steels measured by DTA and calculated using Scheil and Lever rule
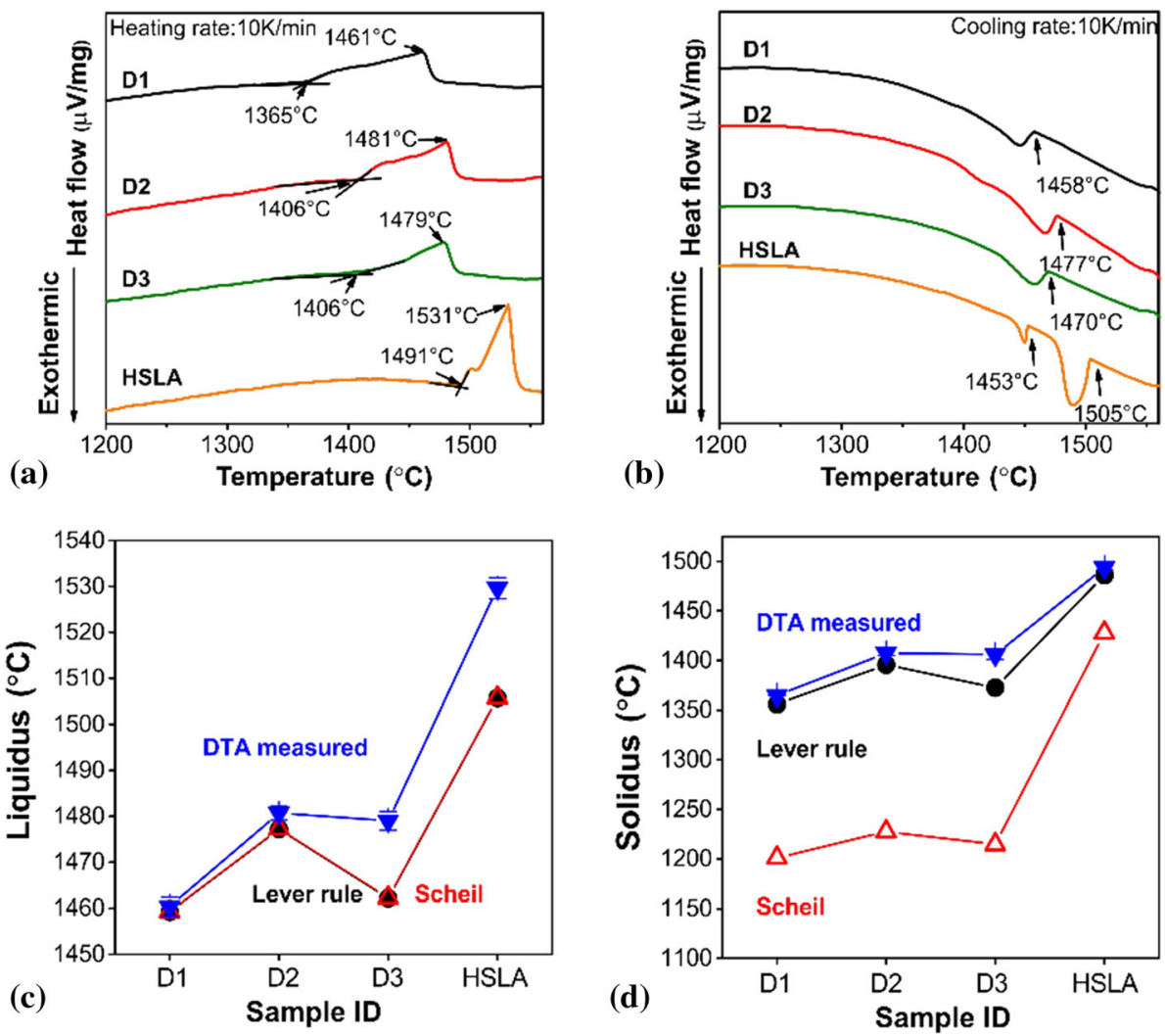

(e)

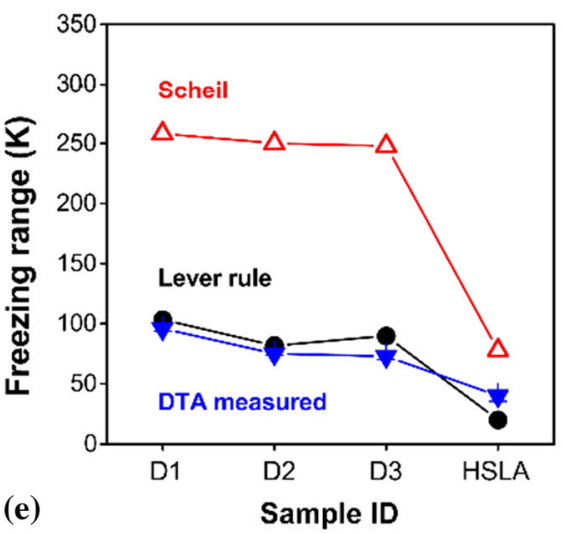

the measured liquidus and solidus will be higher than the true liquidus and solidus, and the amount of deviation is positively related to the heating rate. This is in accordance with our results that DTA measured liquidus and solidus temperatures are higher than the calculated values using Lever rule.

From Fig. 1(e), it is evident that the freezing range of HSLA-115 steel and alloy D1 is the lowest and highest, respectively. The freezing ranges of the other alloys are similar. It can also be observed that the Lever rule shows a good agreement with the value from the DTA heating curves. This indicates that the Lever rule calculation can predict the freezing range accurately in comparison with the Scheil calculations, possibly because of the small sample size and the low heating rate of DTA measurement is closer to the equilibrium state. Moreover, the freezing ranges obtained using all the three methods show a similar tendency with different compositions. The freezing range is crucial in alloy design for casting, welding, and additive manufacturing. As a smaller freezing range indicates a better resistance to hot cracking during welding, ${ }^{[33]}$ few reasons are possibly responsible for the change of freezing range. Firstly, melting of alloys D1-D3 involves complete dissolution of MX (M: ( $\mathrm{Nb}, \mathrm{Ti})$ or Ti only) phase into the matrix that will occur at a higher temperature $\left(<1400{ }^{\circ} \mathrm{C}\right.$, from Fig. 5) in comparison with the other intermetallic phases. This phenomenon is expected to raise the liquidus temperature and, eventually, increase the freezing range. 
Table 3 Transition temperatures determined from DTA experiments as well as predicted from equilibrium and non-equilibrium Scheil calculations

\begin{tabular}{|c|c|c|c|c|}
\hline Method & Sample & Liquidus, ${ }^{\circ} \mathrm{C}$ & Solidus, ${ }^{\circ} \mathrm{C}$ & Freezing range, $\mathrm{K}$ \\
\hline \multirow[t]{4}{*}{ Equilibrium calculation } & D1 & 1459 & 1356 & 103 \\
\hline & D2 & 1477 & 1395 & 82 \\
\hline & D3 & 1462 & 1373 & 90 \\
\hline & HSLA & 1506 & 1486 & 20 \\
\hline \multirow[t]{4}{*}{ Scheil calculation } & D1 & 1459 & 1201 & 258 \\
\hline & D2 & 1477 & 1227 & 250 \\
\hline & D3 & 1462 & 1215 & 248 \\
\hline & HSLA & 1506 & 1428 & 78 \\
\hline \multicolumn{5}{|l|}{ DTA measurement } \\
\hline \multirow[t]{4}{*}{ 1st heating curve } & D1 & 1458 & 1365 & 93 \\
\hline & D2 & 1479 & 1406 & 73 \\
\hline & D3 & 1477 & 1401 & 76 \\
\hline & HSLA & 1527 & 1496 & 31 \\
\hline \multirow[t]{4}{*}{ 2nd heating curve } & D1 & 1461 & 1365 & 96 \\
\hline & D2 & 1481 & 1406 & 75 \\
\hline & D3 & 1479 & 1406 & 73 \\
\hline & HSLA & 1531 & 1491 & 40 \\
\hline \multirow[t]{4}{*}{ 3rd heating curve } & D1 & 1462 & 1364 & 98 \\
\hline & D2 & 1482 & 1410 & 72 \\
\hline & D3 & 1481 & 1410 & 71 \\
\hline & HSLA & 1531 & 1494 & 37 \\
\hline \multirow[t]{4}{*}{ Average \pm standard deviation } & D1 & $1460 \pm 2.1$ & $1364 \pm 0.6$ & $96 \pm 2.5$ \\
\hline & D2 & $1481 \pm 1.5$ & $1407 \pm 2.3$ & $73 \pm 2.5$ \\
\hline & D3 & $1479 \pm 2$ & $1406 \pm 4.5$ & $73 \pm 2.5$ \\
\hline & HSLA & $1530 \pm 2.3$ & $1493 \pm 2.5$ & $36 \pm 4.6$ \\
\hline
\end{tabular}

Secondly, various alloying elements have a different impact on the transition temperatures, which will be discussed below.

In order to understand the influence of alloying elements on the liquidus, solidus and freezing range, high-throughput calculations were performed by considering the composition of the HSLA-115 steel as the base. The amount of each element was varied from 0 to $10 \mathrm{wt} \%$ (Carbon content changes from 0 to $1 \mathrm{wt} . \%$ ), while the contents of other alloying elements were held constant for each set of calculations. In this high-throughput calculation, the 1010 compositions were calculated. The calculated liquidus, solidus and freezing range as a function of the content of each alloying element is illustrated in Fig. 2. It is evident that the addition of carbon will lead to a decrease in both liquidus and solidus temperatures, while the decrease in solidus temperature is more pronounced. As a result, addition of carbon will significantly increase the freezing range leading to poor weldability. Analysis of the effect of other alloying elements was also performed using similar strategy. Figure 2 shows that the liquidus temperature of HSLA-115 is higher. Because it has small amount of $\mathrm{C}, \mathrm{Si}$, $\mathrm{Ti}$ and $\mathrm{Nb}$ that leads to a decrease in the liquidus temperature, and it contains significant amount of $\mathrm{Ni}$ that has a minor effect on lowering the solidus and liquidus temperatures. Further, the ability of the alloying elements to increase the freezing range can be arranged in decreasing order as follows: $\mathrm{C}, \mathrm{Nb}, \mathrm{Ti}, \mathrm{Si}, \mathrm{Mo}, \mathrm{Al}, \mathrm{Cu}, \mathrm{Mn}$, and $\mathrm{Cr}$. Elements such as $\mathrm{Nb}, \mathrm{Ti}$, and $\mathrm{Al}$ will increase the freezing range initially and subsequently, decrease after reaching a threshold value. $\mathrm{Ni}$ is the only alloying element that can decrease the freezing range according to these calculations. Since the HSLA-115 steel has a low content of alloying elements that increase the freezing range such as $\mathrm{C}, \mathrm{Nb}, \mathrm{Ti}$, $\mathrm{Si}$ and $\mathrm{Al}$, and has a large amount of $\mathrm{Ni}$ that can lead to the decrease in freezing range, it has the lowest freezing range amongst all the alloys considered in the present work. On the other hand, D1 has the highest amount of Ti, Al, Si, and $\mathrm{C}$, the lowest amount of $\mathrm{Ni}$. As a result, it has the highest freezing range and may not be a suitable material for manufacturing processes such as additive manufacturing and welding.

In a nutshell, our results indicate that the equilibrium calculations using the Lever rule approach is capable of predicting the freezing ranges, liquidus and solidus temperatures accurately in comparison with the non- 

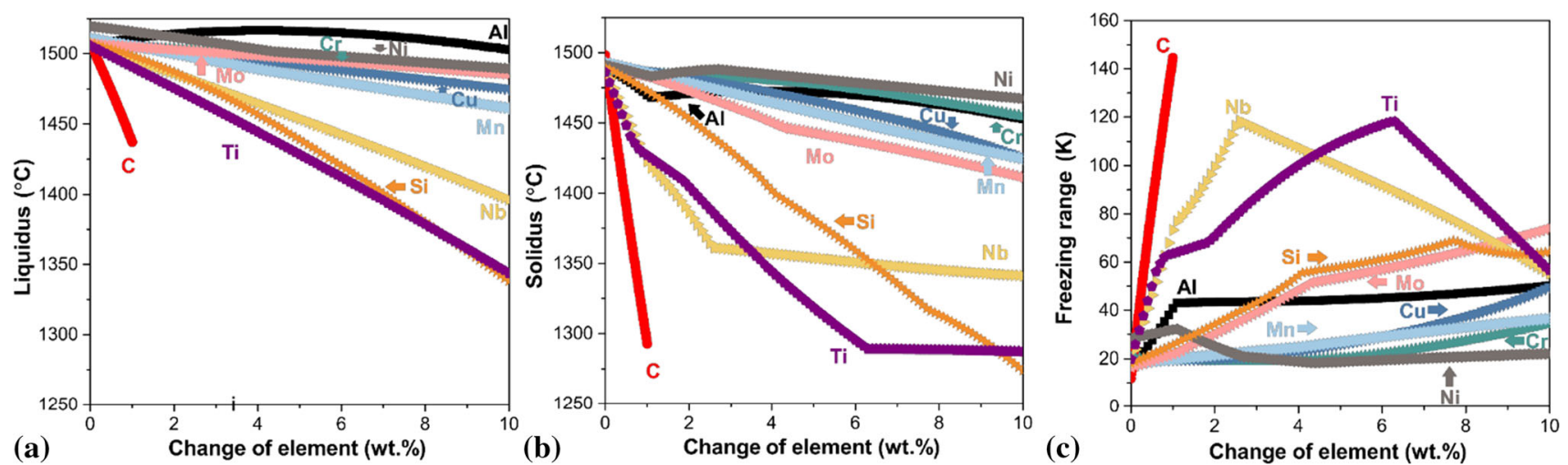

Fig. 2 The influence of each element on the (a) liquidus, (b) solidus and (c) freezing range (each element is varied from 0 to $10 \mathrm{wt} . \%$, carbon is varied from 0 to $1 \mathrm{wt} \%$, while other element contents are the same as the HSLA-115 steel)

equilibrium Scheil simulations while using the DTA heating signals as reference. In addition, it is observed that many cooling signals are too weak to assist in freezing range estimation for comparison with the Scheil-Gulliver non-equilibrium simulations, while analysis from DTA heating signals matches the calculated results. Therefore, the DTA heating signal and CALPHAD-based calculations are useful for guiding the design of new alloys and also prove helpful in identifying whether a newly designed composition is suitable for welding and additive manufacturing processes.

\subsection{Validation of Phase Transformations}

\subsubsection{As-Cast Designed and Conventional HSLA-115 Steels}

The calculated Scheil solidification diagrams and the SEM/ BSE images of the designed alloys and HSLA-115 steel in the as-cast state are shown in Fig. 3 and 4, respectively. According to the Scheil solidification diagrams for alloys D1 and D2 (Fig. 3a and b), the as-cast microstructure of D1 and D2 alloys should consist of Laves_C14 $\left(\mathrm{Fe}_{2} \mathrm{Ti}\right)$ and $(\mathrm{Nb}, \mathrm{Ti}) \mathrm{C}$ phases dispersed in a ferrite matrix. However, from the SEM/BSE images (Fig. 4a and b), it is evident that the as-cast microstructure of alloy D1 consists of $\mathrm{Fe}_{2} \mathrm{SiTi}$ and Laves_C14 phases. D2 alloy only comprises of the Laves_C14 within the ferrite matrix. The presence of the carbide phase $(\mathrm{Nb}, \mathrm{Ti}) \mathrm{C}$ was not detected under the SEM, probably due to its small size and fraction. Some of the $\mathrm{Fe}_{2} \mathrm{SiTi}$ precipitates within the grains of alloy D1 are found to be coarsened and surrounded by a denuded zone without any small precipitates. In alloy D2, the fine Laves_C14 phase is scarcely distributed within the grains. Continuous precipitates of $\mathrm{Fe}_{2} \mathrm{SiTi} / \mathrm{Laves}$ _C14 phase in alloy D1, as well as Laves_C14 phase in alloy D2, are found to form in the grain boundaries of these alloys.
Table 4 summarizes the composition and fraction of each phase determined experimentally and calculated using Scheil simulations at the end of solidification for the as-cast designed alloys and HSLA-115 steel. $\mathrm{Fe}_{2} \mathrm{SiTi}$ is considered to be a thermodynamically metastable phase. ${ }^{[34]}$ It is to be noted that the prediction of metastable phases is possible only if a constrained Scheil simulation is performed after suspending the equilibrium phases that are responsible for suppressing the metastable phase formation. ${ }^{[35]}$ Since the phases to be suspended to allow the formation of $\mathrm{Fe}_{2} \mathrm{SiTi}$ is unknown, its formation is not predicted from the nonequilibrium Scheil simulations for alloy D1. Moreover, the calculated Si composition of the Laves_C14 phase for alloy D1 is moderately high ( $>10$ at.\%). It has also been reported that an extended solid solubility of $\mathrm{Si}(\sim 27 \%$ from 800 to $1150{ }^{\circ} \mathrm{C}$ ) into the $\mathrm{Fe}$ sublattice of $\mathrm{Fe}_{2} \mathrm{Ti}$ Laves phase $\left((\mathrm{Fe}, \mathrm{Si})_{2} \mathrm{Ti}\right)$ has been observed using experiments in Fe-Si-Ti alloys. ${ }^{[36,37]}$ The Si-rich $\mathrm{Fe}_{2} \mathrm{Ti}$ phase might have possibly transformed into the $\mathrm{Fe}_{2} \mathrm{SiTi}$ phase due to interdiffusion. This can be postulated since both Laves_C14 and $\mathrm{Fe}_{2} \mathrm{SiTi}$ phases are found to be coexisting in the SEM/BSE images for D1 alloys (the encircled region in Fig. 4a), with the former in the core and the latter forming a shell around it. A similar observation has been reported for the Ni-Al-Ta system, where the $(\mathrm{Ni}, \mathrm{Al})_{2} \mathrm{Ta}$ Laves_C14 phase transforms to the $\mathrm{Ni}_{2} \mathrm{TaAl}$ Heusler phase with $\mathrm{L}_{1}$ structure due to interdiffusion. ${ }^{[38]}$ From the experimentally determined compositions for the Laves_C14 and $\mathrm{Fe}_{2} \mathrm{SiTi}$ phases, it is evident that there is a dissolution of $\mathrm{Nb}$ into these phases, possibly into the Ti sublattice due to their chemical similarities. It can also be observed that the measured composition of $\mathrm{Fe}$ is higher in the $\mathrm{Fe}_{2} \mathrm{SiTi}$ phase. This is because the precipitates are small and the minimum electron beam diameter for EDS measurement is larger than the precipitate size. Hence, it is possible that some of the characteristic X-rays from the matrix could have been detected along the X-rays from the precipitates leading to detection 
Fig. 3 Calculated Scheil solidification diagram for (a) D1, (b) D2, (c) D3, and (d) HSLA-115 steels
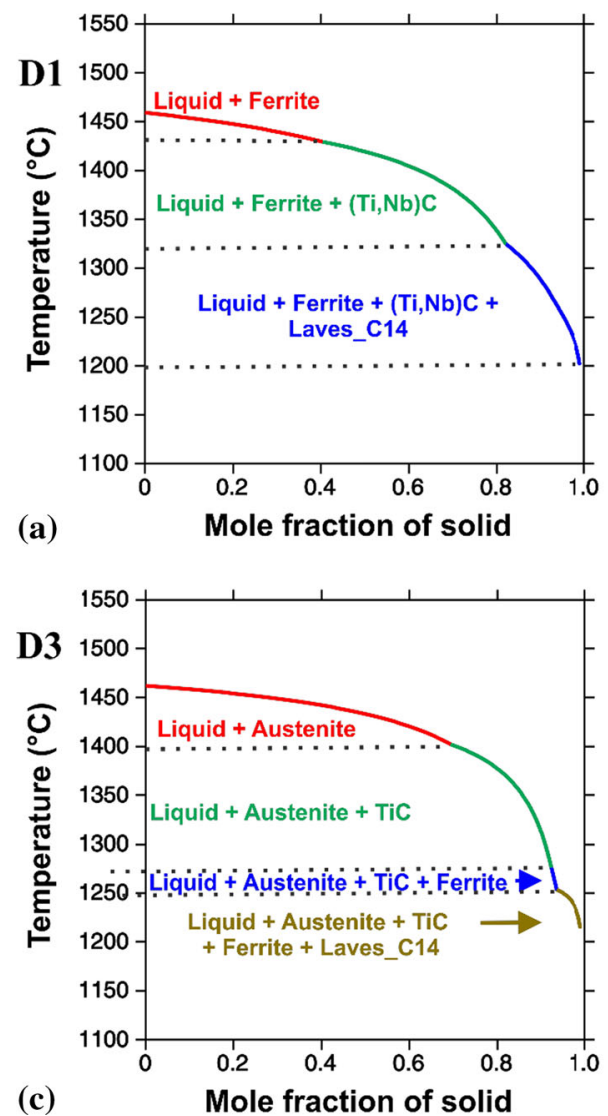

Fig. 4 SEM/BSE micrographs of as-cast (a) D1 (encircled region indicate precipitates with coexisting $\mathrm{Fe}_{2} \mathrm{SiTi}$ and Laves phase), (b) D2, (c) D3 (inset image showing small sized Laves_C14 phase particles forming clusters), and (d) HSLA-115 steels of increased $\mathrm{Fe}$ content in these precipitates. Moreover, the formation of significant amount of $\mathrm{Fe}_{2} \mathrm{SiTi}$ in as-cast D1 alloy, reduces the amount of Laves_C14 phase that forms during the solidification. However, the formation of

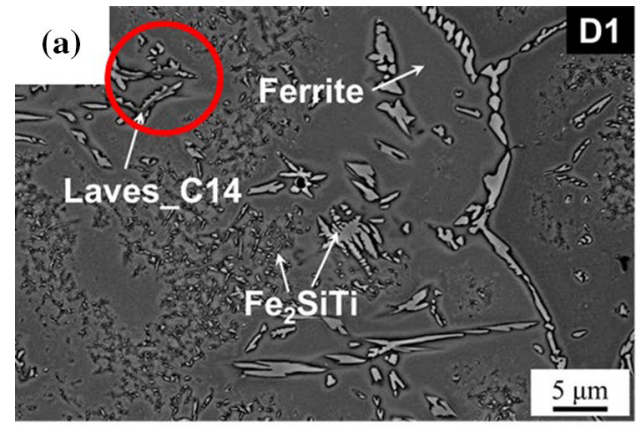

(c)
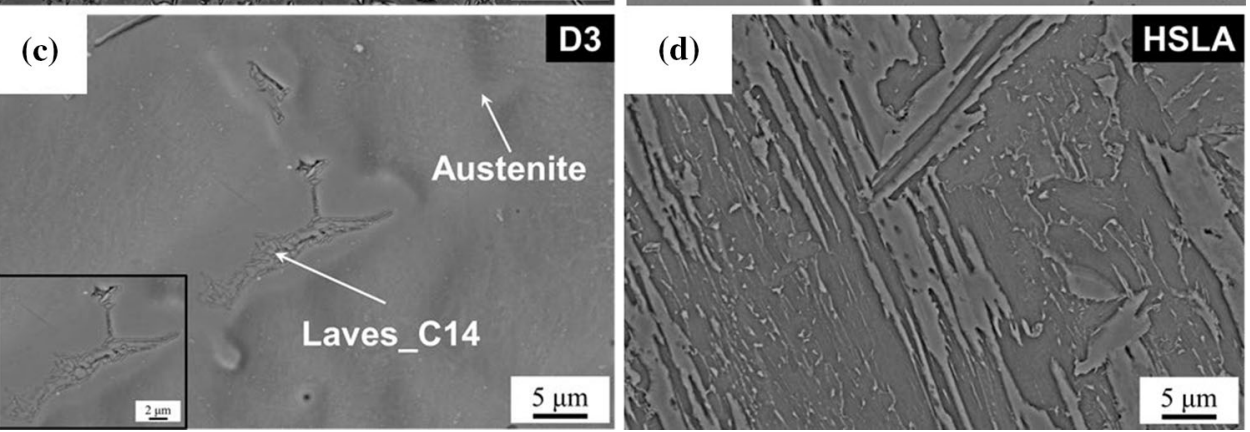
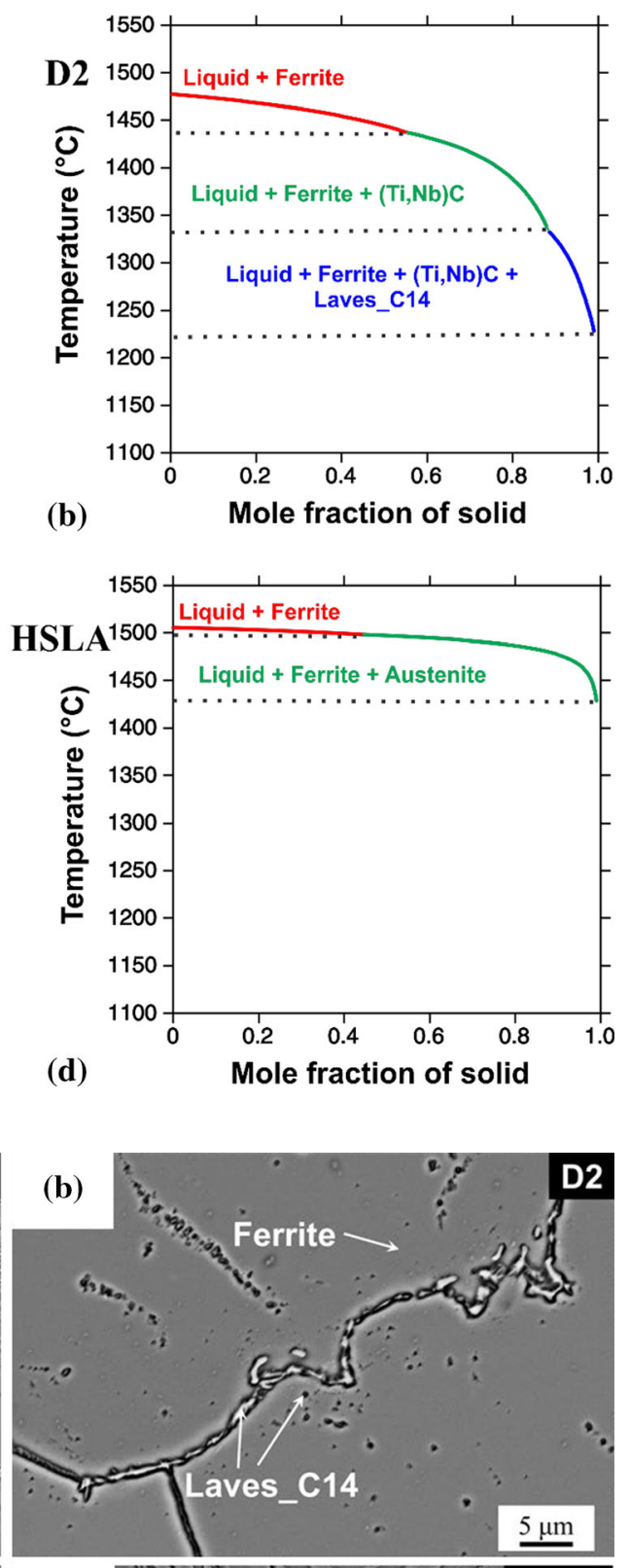

(d)

Mole fraction of solid
$\mathrm{Fe}_{2} \mathrm{SiTi}$ phase is not predicted in the non-equilibrium Scheil simulation for D1 alloy. Hence, the experimental and calculated phase fractions do not correlate well for D1 alloy. On the contrary, a good correlation is observed 


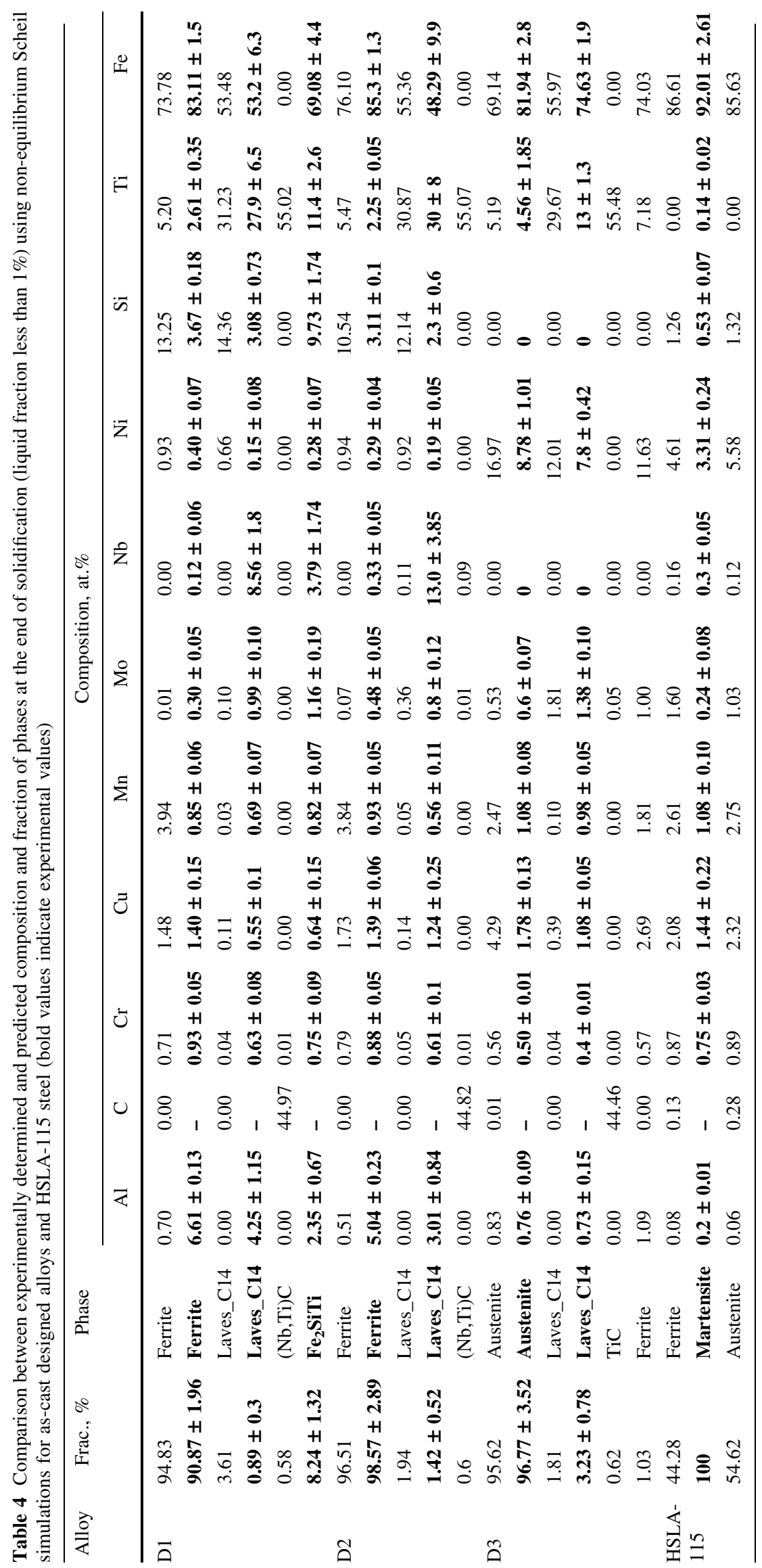


between the predicted and experimental phase fractions in the as-cast D2 alloy since the minor amounts of $(\mathrm{Nb}, \mathrm{Ti}) \mathrm{C}$ cannot be resolved using SEM.

From the Scheil-Gulliver solidification diagram (Fig. 3c) and SEM/BSE image (Fig. 4c), it is clear that there is only a minor difference between the model-predicted and experimentally determined phase evolution in alloy D3 since the phases in smaller fractions are hard to be resolved. The as-cast microstructure consists of clusters of small Laves_C14 phase particles (average size $\approx 2 \mu \mathrm{m}$ ) dispersed in an austenite matrix as shown in the inset of Fig. 4(c). The as-cast microstructure of HSLA-115 steel (Fig. 4d) is completely martensitic. However, Scheil-Gulliver simulation (Fig. 3d) predicts that the primary phase to solidify from the liquid is ferrite, followed by the solidification of austenite. It is expected that the high temperature ferrite that forms during the initial stage of solidification can transform to austenite through a nonequilibrium transformation along with the formation of austenite from liquid. This results in a completely martensitic microstructure due to the rapid cooling of austenite. As a result of the poor correlation between the predicted and observed phase evolution, the experimentally determined and calculated phase compositions are also not in agreement with each other, as it can be observed from the values listed in Table 4 for alloy D3 and HSLA-115 steel, respectively. However, there is a fairly good agreement between the experimental and calculated fraction of phases for as-cast alloy D3 as the minor fractions of TiC and ferrite are not possible to be resolved using SEM and a poor correlation is observed for as-cast HSLA-115 steel.

\subsubsection{Long-Term Heat-Treated Designed and Conventional HSLA-115 Steels}

The calculated equilibrium phase fraction as a function of temperature using the CALPHAD method and the SEM/ BSE micrographs after long-term heat treatment for the designed alloys and HSLA-115 steel are shown in Fig. 5 and 6, respectively. From the equilibrium phase fraction plots for D1 and D2 alloys (Fig. 5a and b), it is evident that the equilibrium microstructure at $600{ }^{\circ} \mathrm{C}$ should comprise of $\mathrm{Fe}_{2} \mathrm{SiTi}$ and Laves_C14 phase as the major secondary phases with minor amounts of $\mathrm{Cu}$ and $(\mathrm{Nb}, \mathrm{Ti}) \mathrm{C}$ phases, dispersed in a ferrite matrix. According to the SEM/BSE observation, the microstructure after long-term heat treatment at $600{ }^{\circ} \mathrm{C}$ consists of $\mathrm{Fe}_{2} \mathrm{SiTi}$ and Laves phase in a ferrite matrix for alloys D1 and D2 (Fig. 6a and b). Similar to the HSLA-115 steels, the fraction and size of the minor phases such as $\mathrm{Cu}$ and $(\mathrm{Nb}, \mathrm{Ti}) \mathrm{C}$ are too small to be visible under a scanning electron microscope. ${ }^{[39-41]}$ Hence, there is a good correlation between the experimentally observed and predicted phase evolution of these alloys at $600{ }^{\circ} \mathrm{C}$.
From Fig. 6(a) and (b), it can be observed that the $\mathrm{Fe}_{2} \mathrm{SiTi}$ and Laves_C14 phase form in the grain boundaries as well as within the grains. The Laves phase co-exists only within the blocky $\mathrm{Fe}_{2} \mathrm{SiTi}$ particles (encircled regions in Fig. 6a), similar to the as-cast alloys. Since D1 alloy consists of a higher fraction of blocky $\mathrm{Fe}_{2} \mathrm{SiTi}$ precipitates (Fig. 6a), the amount of the Laves_C14 phase is found to be higher. Moreover, the thickness of the continuous precipitates of the $\mathrm{Fe}_{2} \mathrm{SiTi}$ phase along the grain boundaries is larger. The higher fraction of precipitates in the D1 alloy is possibly due to the presence of a higher amount of $\mathrm{Ti}, \mathrm{Si}$, and $\mathrm{Al}$ in comparison with the D2 alloy. On the other hand, D2 alloy consists of thin and continuous $\mathrm{Fe}_{2} \mathrm{SiTi}$ precipitates along the grain boundaries and scarcely dispersed fine precipitates of $\mathrm{Fe}_{2} \mathrm{SiTi}$ as well as the slightly bigger precipitates of $\mathrm{Fe}_{2} \mathrm{SiTi} /$ Laves_C14 phase within the grains (Fig. 6b).

The experimentally determined and calculated phase fractions and compositions using equilibrium thermodynamic calculations for the designed alloys and HSLA-115 steel are summarized in Table 5. It is evident that there is an unsatisfactory agreement between the experimental and model-predicted fractions and compositions of the constituent phases. Compared with experimental results, the calculated fractions of the $\mathrm{Fe}_{2} \mathrm{SiTi}$ phase are underestimated, and the fractions of the Laves_C14 phase are overestimated for both D1 and D2 alloys. However, the predicted and experimentally measured phase fraction of $\mathrm{Fe}_{2} \mathrm{SiTi}$ shows the same trend, i.e., D1 > D2, indicating that the CALPHAD method can be used to guide the alloy design more qualitatively rather than quantitatively in this case. It can also be observed that there is a significant dissolution of $\mathrm{Nb}$ into the Laves_C14 phase ( $\sim 9$ to 13 at.\%) and dissolution of $\mathrm{Nb}$ and $\mathrm{Al}$ into the $\mathrm{Fe}_{2} \mathrm{SiTi}$ phase ( 2 to 3 at.\%), possibly into the Ti sublattice of both the phases due to their chemical similarities. However, the dissolution of $\mathrm{Nb}$ and $\mathrm{Al}$ into the $\mathrm{Fe}_{2} \mathrm{SiTi}$ phase has not been taken into account in the currently available commercial thermodynamic database for steels.

The calculated equilibrium phase fractions as a function of temperature for D3 alloy (Fig. 5c) shows that at $600{ }^{\circ} \mathrm{C}$, the equilibrium phases are ferrite, austenite, $\mathrm{Cu}, \mathrm{TiC}$, and Laves_C14 phase. However, from the SEM/BSE micrograph (Fig. 6c), it is evident that the microstructure consists of clusters of Laves_C14 phase and fine needle-shaped $\mathrm{Ni}_{3} \mathrm{Ti}$ phase dispersed in an austenite matrix. The $\mathrm{Ni}_{3} \mathrm{Ti}$ phase is found to be stable at the heat treatment temperature, which is higher than the dissolution temperature (570 $\left.{ }^{\circ} \mathrm{C}\right)$ estimated using the thermodynamic calculation (Fig. 5c). Therefore, there is a poor correlation between the experimentally observed phase evolution and the equilibrium phases predicted for the D3 alloy. This proves that computational predictions are not exact in all the cases and 
Fig. 5 Calculated equilibrium phase fraction plots for (a) D1, (b) D2, (c) D3, and (d) HSLA115 steels as a function of temperature
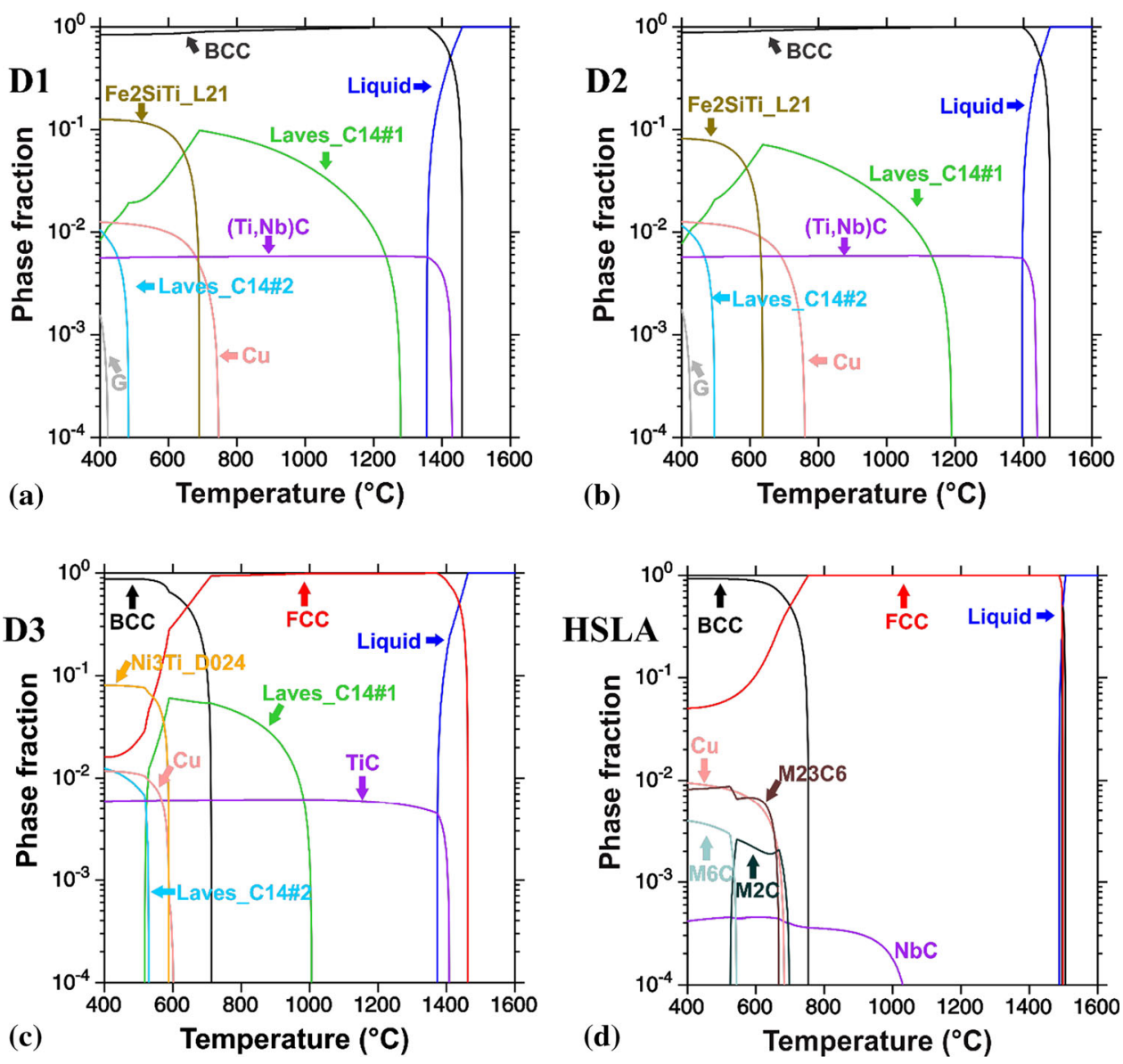

Fig. 6 SEM/BSE micrographs of (a) D1 (encircled region indicate precipitates with coexisting $\mathrm{Fe}_{2} \mathrm{SiTi}$ and Laves phase), (b) D2, (c) D3, and (d) HSLA-115 steels after long term heat treatment at $600{ }^{\circ} \mathrm{C}$
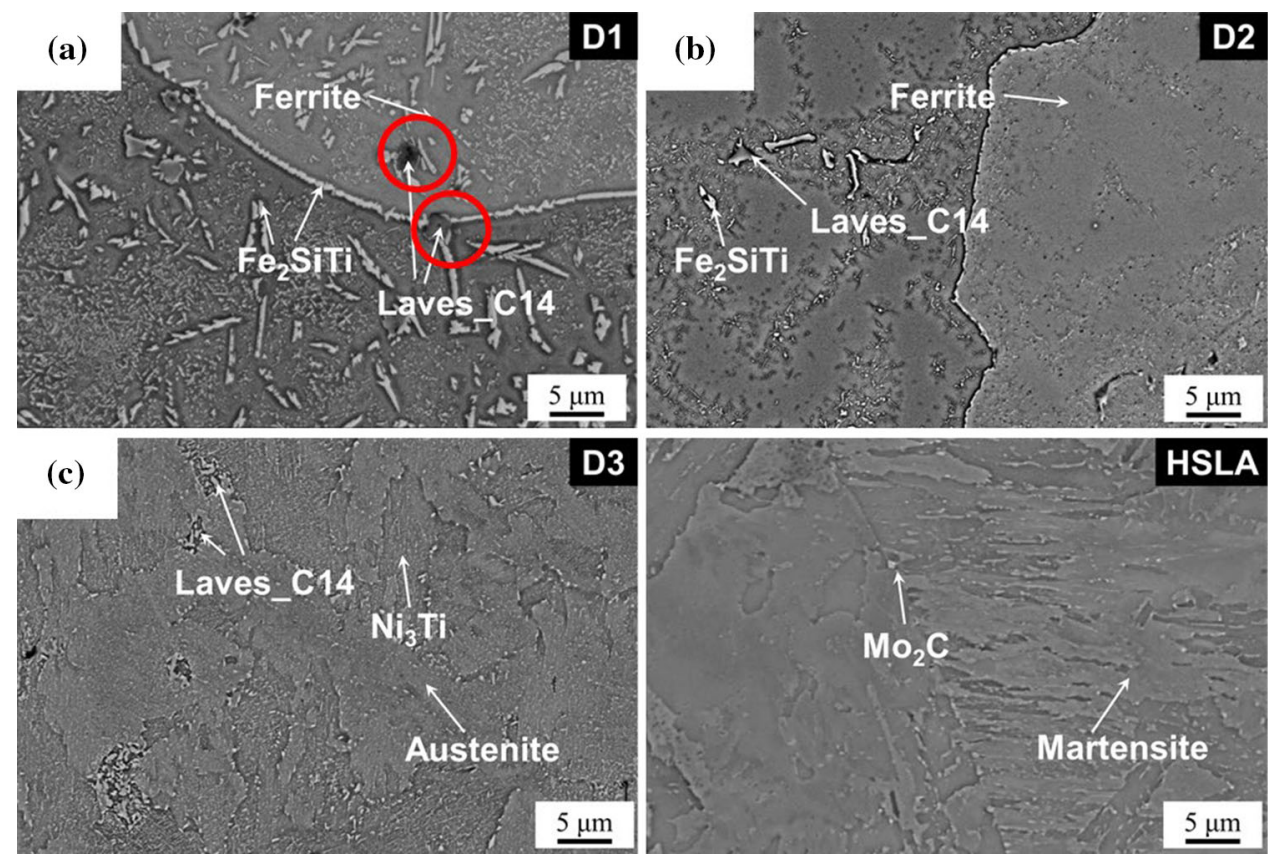


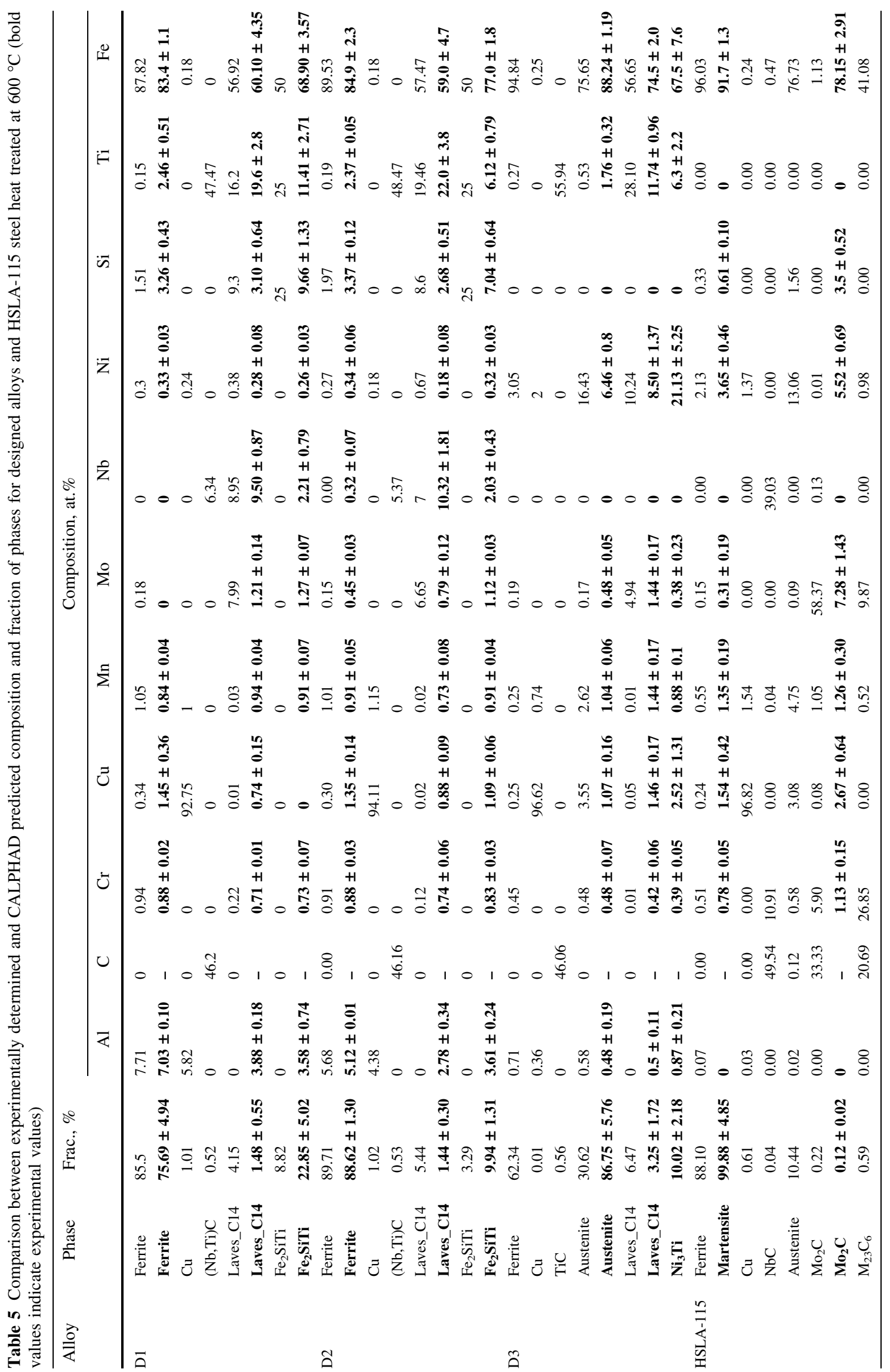


also necessitates the importance of calibration experiments for materials design using computational methods in practice. $\mathrm{Ni}_{3} \mathrm{Ti}$ has been reported as a strengthening phase in some of the austenitic steels. ${ }^{[23,24]}$ Hence, due to the presence of this phase in needle-shaped morphology in the austenite matrix, this alloy is expected to exhibit excellent mechanical properties due to the strengthening effects achieved by precipitation hardening. In addition, from Table 5, it is obvious that there is a marked difference between the calculated and experimentally measured fractions and compositions of the constituent phases for alloy D3. It can also be observed that the measured composition of $\mathrm{Fe}$ in $\mathrm{Ni}_{3} \mathrm{Ti}$ precipitate is high, similar to $\mathrm{Fe}_{2-}$ SiTi precipitates in D1 and D2 alloys which is due to the larger diameter of electron beam in comparison with the precipitate size. Hence, the Fe content is high, although the ratio between the measured compositions of $\mathrm{Ni}$ and $\mathrm{Ti}$ is close to the stoichiometry of $\mathrm{Ni}_{3} \mathrm{Ti}$.

The predicted equilibrium phases for the HSLA-115 steel (Fig. 5d) at $600{ }^{\circ} \mathrm{C}$ are ferrite, austenite, $\mathrm{Cu}, \mathrm{Mo}_{2} \mathrm{C}$, and $\mathrm{M}_{23} \mathrm{C}_{6}(\mathrm{M}: \mathrm{Cr}, \mathrm{Fe})$. The SEM/BSE micrograph (Fig. 6d) shows the presence of very small precipitates of $\mathrm{Mo}_{2} \mathrm{C}$ dispersed in a martensitic matrix after longterm heat treatment at $600{ }^{\circ} \mathrm{C}$. Since the phase fraction of $\mathrm{Cu}$ and $\mathrm{NbC}$ precipitates are small, other sophisticated characterization techniques are required to detect these phases. ${ }^{[39,41]}$ The calculated driving force using the Thermo-Calc software for the formation of $\mathrm{Mo}_{2} \mathrm{C}$, $\mathrm{M}_{23} \mathrm{C}_{6}$, and austenite were 24378, 7313, and $2631 \mathrm{~J} / \mathrm{mol}$, respectively. Hence, it is clearly evident that the formation of $\mathrm{Mo}_{2} \mathrm{C}$ is more favorable in comparison with $\mathrm{M}_{23} \mathrm{C}_{6}$ and austenite, which is in accordance with the microstructure obtained after long-term heat treatment at $600{ }^{\circ} \mathrm{C}$ (Fig. 6d). Therefore, there is a good correlation between the experimentally observed and predicted phase evolution for HSLA-115 steel. Besides, there is a fairly good agreement between the experimental and predicted phase fractions and composition for the individual phases for the HSLA-115 steel, as it can be seen from Table 5.

From the experimentally observed and predicted phase evolution as well as fraction and composition of the constituent phases for the as-cast and long-term heat-treated alloys, it is obvious that there is a need to improve the multicomponent thermodynamic database, and thus, achieve reliable predictions for steels designed with unconventional strengthening precipitates. An accurate prediction by equilibrium thermodynamic calculations and non-equilibrium Scheil simulations will be helpful in reducing the efforts involved in alloy design and process optimization. Moreover, it will increase the efficiency of screening the compositions using high-throughput calculations to design new alloys. This will be helpful in achieving the desired microstructure with fewer experimental attempts leading to lower costs.

\section{Summary and Conclusions}

In this work, the transition temperatures and phase transformations in HSLA steels designed with alternative strengthening precipitates such as $\mathrm{Fe}_{2} \mathrm{SiTi}$ and $\mathrm{Ni}_{3} \mathrm{Ti}$ as well as conventional HSLA-115 steel were investigated and compared with the predictions from equilibrium thermodynamic calculations and non-equilibrium simulations using the Scheil-Gulliver model. Based on the analysis presented above, the significant outcomes from the present study can be summarized as follows:

- A good correlation was observed for the liquidus and solidus temperatures as well as the freezing ranges measured using DTA heating signals and the corresponding values calculated using the Lever rule method. The freezing range from Scheil simulations were overestimated due to the underlying assumptions used in the Scheil-Gulliver model.

- The freezing range of D1 alloy was the largest because of the presence of a higher amount of alloying elements such as $\mathrm{Ti}, \mathrm{Si}, \mathrm{Al}$, and $\mathrm{C}$. The lowest freezing range was observed for HSLA-115 steel owing to the higher Ni content and low content of other alloying elements. The freezing ranges for other alloys were similar.

- A poor correlation was observed between the phase evolution and composition of constituent phases determined experimentally for the as-cast alloys and predicted quantities using the non-equilibrium Scheil simulations for the designed alloys and the HSLA-115 steel.

- There is a good agreement between the phase evolution determined from microstructure characterization, and the equilibrium phases predicted using the thermodynamic calculations only for alloys with $\mathrm{Fe}_{2} \mathrm{SiTi}$ precipitates and HSLA-115 steel. However, a notable difference can be observed between the experimental and calculated phase fractions and compositions for the steel designed with the $\mathrm{Ni}_{3} \mathrm{Ti}$ precipitates.

- These observations indicate that further improvement is required for the multicomponent CALPHAD database to guide the design of microstructure engineering of steels with unconventional strengthening precipitates in as-cast and heat-treated conditions.

Acknowledgments The authors would like to gratefully acknowledge the financial support received from the Office of Naval Research Additive Manufacturing Alloys for Naval Environments (AMANE) program (Contract No. N00014-17-1-2586). The authors also thank Ms. Shiyu Fu for her assistance in alloy preparation. W.X. would like 
to use this work in honor of the 2019 J. Willard Gibbs Phase Equilibria Award Winner, Dr. Patrice E. A. Turchi.

\section{References}

1. T.W. Montemarano, B.P. Sack, J.P. Gudas, M.G. Vassilaros, and H.H. Vanderveldt, High Strength Low Alloy Steels in Naval Construction, J. Sh. Prod., 1986, 2, p 145-162

2. E.J. Czyryca, R.E. Link, R.J. Wong, D.A. Aylor, J.P. Montemarano, and T.W. Gudas, Development and Certification of HSLA-100 Steel for Naval Ship Construction, Nav. Eng. J., 1990, 102, p 63-82

3. T. Anderson, J. Hyatt, and J. West, The Benefits of New HighStrength Low-Alloy (HSLA) Steels, Weld. J., 1987, 66, p 21-26

4. M. Mujahid, A.K. Lis, C.I. Garcia, and A.J. DeArdo, HSLA-100 Steels: Mcrostructure and Properties, Key Eng. Mater., 1993, 84-85, p 209-236. https://doi.org/10.4028/www.scientific.net/ kem.84-85.209

5. M.D. Mulholland and D.N. Seidman, Nanoscale Co-Precipitation and Mechanical Properties of a High-Strength Low-Carbon Steel, Acta Mater., 2011, 59, p 1881-1897. https://doi.org/10.1016/j. actamat.2010.11.054

6. B.A. Graville, Welding of HSLA (Microalloyed) Structural Steels, in: ASM Int., 1976, pp. 85-101.

7. L.J. Cuddy and J.C. Raley, Austenite Grain Coarsening in Microalloyed Steels, Metall. Trans. A, 1983, 14, p 1989-1995. https://doi.org/10.1007/BF02662366

8. D. Schwartz and B. Ralph, The Early Stages of Growth of Second-Phase Particles in an Fe-Ti-Si alloy, Methods Sci. J., 1969, 3, p 216-219

9. D.H. Jack and R.W.K. Honeycombe, Age Hardening of an Fe-TiSi Alloy, Acta Metall., 1972, 20, p 787-796. https://doi.org/10. 1016/0001-6160(72)90126-5

10. M. Perrier, O. Bouaziz, Y. Brechet, A. Deschamps, and P. Donnadieu, Mechanical Properties of Low Carbon Steel Hardened by the Fe 2SiTi Phase at High Volume Fraction, J. Phys. Conf. Ser., 2010, 240, p 1047-1064. https://doi.org/10.1088/17426596/240/1/012095

11. R. Wasmuht, Die Ausscheidungshärtung des Eisens durch Titan, Arch. Fur Das Eisenhuttenwes., 1931, 5, p 45-46

12. J. Henon, C. Wache, and J. Manenc, Etude de la Precipitation Dans Les Alliages Fe-Ti, Fe-Ti-Si, Fe-Ti-Ni, Mem. Sci. Rev. Met., 1966, 63, p 99-108

13. D. Abson, G. Brown, and J. Whiteman, Precipitation of Intermetallic Compounds in Some Ferritic Ternary Alloys, J. Aust. Inst. Met., 1968, 13, p 61

14. D.H. Jack, Intermetallic Precipitate in an Fe-Ti-Si Alloy, Met. Sci. J., 1970, 4, p 22-24. https://doi.org/10.1179/msc.1970.4.1.22

15. M. Perrier, A. Deschamps, O. Bouaziz, Y. Brechet, F. Danoix, F. De Geuser, P. Donnadieu, K. Hoummada, and P. Maugis, Characterization and modeling of precipitation kinetics in a $\mathrm{Fe}-\mathrm{Si}-\mathrm{Ti}$ alloy, Metall. Mater. Trans. A Phys. Metall. Mater. Sci., 2012, 43, p 4999-5008. https://doi.org/10.1007/s11661-012-1337-8

16. Y. Zhang and J. Yang, Formation of $\mathrm{Nb}(\mathrm{C}, \mathrm{N})$ Carbonitride in Cast Austenitic Heat-Resistant Steel During Directional Solidification Under Different Withdraw Rates, Materials (Basel)., 2018, https://doi.org/10.3390/ma11122397

17. Y. Zhang, M. Li, L.A. Godlewski, J.W. Zindel, and Q. Feng, Effects of $\mathrm{W}$ on Creep Behaviors of Novel Nb-Bearing High Nitrogen Austenitic Heat-Resistant Cast Steels at $1000{ }^{\circ} \mathrm{C}$, Mater. Charact., 2018, 139, p 19-29. https://doi.org/10.1016/J. MATCHAR.2018.02.027

18. Y. Zhang, M. Li, L.A. Godlewski, J.W. Zindel, and Q. Feng, Effects of N/C Ratio on Solidification Behaviors of Novel Nb-
Bearing Austenitic Heat-Resistant Cast Steels for Exhaust Components of Gasoline Engines. Metall, Mater. Trans. A Phys. Metall. Mater. Sci., 2017, 48, p 1151-1162. https://doi.org/10. 1007/s11661-016-3920-x

19. Y. Zhang and J. Yang, CALPHAD-Based Alloy Design of Cast Austenitic Heat-Resistant Steels with Enhanced Strength at 1000 ${ }^{\circ} \mathrm{C}$, Calphad., 2019, 67, p 101679. https://doi.org/10.1016/J. CALPHAD.2019.101679

20. Y.H. Zhang, M. Li, L.A. Godlewski, J.W. Zindel, and Q. Feng, Effective Design of New Austenitic Cast Steels for Ultra-High Temperature Automotive Exhaust Components Through Combined CALPHAD and Experimental Approaches, Mater. Sci. Eng. A, 2017, 683, p 195-206. https://doi.org/10.1016/J.MSEA. 2016.12.023

21. W. Xiong and G.B. Olson, Integrated Computational Materials Design for High-Performance Alloys, MRS Bull., 2015, 40, p 1035-1043. https://doi.org/10.1557/mrs.2015.273

22. W. Xiong and G.B. Olson, Cybermaterials: Materials by Design and Accelerated Insertion of Materials, NPJ Comput. Mater., 2016, https://doi.org/10.1038/npjcompumats.2015.9

23. V.K. Vasudevan, S.J. Kim, and C.M. Wayman, Precipitation reactions and strengthening behavior in $18 \mathrm{Wt}$ Pct nickel maraging steels, Metall. Trans. A Phys. Metall. Mater. Sci., 1990, 21, p 2655-2668. https://doi.org/10.1007/bf02646061

24. H. Li, H. Song, and W. Liu, Precipitation of $\eta-\mathrm{Ni} 3(\mathrm{Ti}, \mathrm{Al})$ Phase at Grain Boundaries in an Austenitic PrecipitationStrengthened Stainless Steel, Metall. Mater. Trans. A Phys. Metall. Mater. Sci., 2019, 50, p 915-923. https://doi.org/10. 1007/s11661-018-5045-x

25. Y.G. Kim, G.S. Kim, C.S. Lee, and D.N. Lee, Microstructure and Mechanical Properties of a Cobalt-Free Tungsten-Bearing Maraging Steel, Mater. Sci. Eng., 1986, 79, p 133-140. https:// doi.org/10.1016/0025-5416(86)90396-4

26. X. Wang, W. Xiong, Design of High-Strength Low Alloy Steels with Alternative Strengthening Precipitates Using CALPHADBased ICME Framework (2020) (unpublished data).

27. W.J. Boettinger, U.R. Kattner, K.-W. Moon, J.H. Perepezko, Chapter5-DTA and Heat-Flux DSC Measurements of Alloy Melting AND Freezing, in: J.-C.B.T.-M. for P.D.D. Zhao (Ed.), Elsevier, Oxford, 2007, pp. 151-221. https://doi.org/10.1016/ B978-008044629-5/50005-7.

28. B. Sundman, B. Jansson, and J.-O. Andersson, The Thermo-Calc Databank System, Calphad., 1985, 9, p 153-190

29. E. Scheil, Bemerkungen zur schichtkristallbildung, Zeitschrift Für Met., 1942, 34, p 70-72

30. G. Gulliver, The Quantitative Effect of Rapid Cooling Upon the Constitution of Binary Alloys, J. Inst. Met., 1913, 9, p 120-157

31. H. Meco and R.E. Napolitano, Liquidus and Solidus Boundaries in the Vicinity of Order-Disorder Transitions in the Fe-Si System, Scr. Mater., 2005, 52, p 221-226

32. W.J. Boettinger and U.R. Kattner, On Differential Thermal Analyzer Curves for the Melting and Freezing of Alloys, Metall. Mater. Trans. A, 2002, 33, p 1779-1794. https://doi.org/10.1007/ s11661-002-0187-1

33. Z. Wu, S.A. David, Z. Feng, and H. Bei, Weldability of a High Entropy CrMnFeCoNi Alloy, Scr. Mater., 2016, 124, p 81-85. https://doi.org/10.1016/j.scriptamat.2016.06.046

34. F. Weitzer, J.C. Schuster, M. Naka, F. Stein, and M. Palm, On the Reaction Scheme and Liquidus Surface in the Ternary System FeSi-Ti, Intermetallics, 2008, 16, p 273-282. https://doi.org/10. 1016/j.intermet.2007.10.006

35. J. Gröbner, S. Zhu, J.-F. Nie, M.A. Gibson, and R. Schmid-Fetzer, Metastable Phase Formation in Ternary Mg-Gd-Zn Alloys, $J$. Alloys Compd., 2016, 675, p 149-157. https://doi.org/10.1016/J. JALLCOM.2016.03.106 
36. F. Löffler, M. Palm, and G. Sauthoff, Iron-Rich Iron-TitaniumSilicon Alloys with Strengthening Intermetallic Laves Phase Precipitates, Steel Res. Int., 2004, 75, p 766-772. https://doi.org/ 10.1002/srin.200405840

37. F. Stein, M. Palm, and G. Sauthoff, Structure and Stability of Laves Phases Part II, - Structure Type Variations in Binary and Ternary Systems, Intermetallics, 2005, 13, p 1056-1074. https:// doi.org/10.1016/j.intermet.2004.11.001

38. M.R. McGregor, M.E. Hancock, L. Pallett, and W.J. Clegg, Examination of Ni-Based Superalloy/Intermetallic Diffusion Couples Containing Multiphase Regions, Intermetallics, 2019, 113, p 106559. https://doi.org/10.1016/j.intermet.2019.106559

39. D. Jain, D. Isheim, and D.N. Seidman, Carbon Redistribution and Carbide Precipitation in a High-Strength Low-Carbon HSLA-115
Steel Studied on a Nanoscale by Atom Probe Tomography, Metall. Mater. Trans. A, 2017, 48, p 3205-3219. https://doi.org/10. 1007/s11661-017-4129-3

40. H. Bhadeshia and R. Honeycombe, Steels: Microstructure and Properties, Butterworth-Heinemann, Oxford, 2017

41. D. Jain, D. Isheim, A.H. Hunter, and D.N. Seidman, Multicomponent High-Strength Low-Alloy Steel Precipitation-Strengthened by Sub-Nanometric $\mathrm{Cu}$ Precipitates and M2C Carbides, Metall, Mater. Trans. A Phys. Metall. Mater. Sci., 2016, 47, p 3860-3872. https://doi.org/10.1007/s11661-016-3569-5

Publisher's Note Springer Nature remains neutral with regard to jurisdictional claims in published maps and institutional affiliations. 